\title{
Insight into the structure of vanadium containing glasses: A molecular dynamics study
}

\author{
Guido Ori ${ }^{\mathrm{a}, *}$, Monia Montorsi ${ }^{\mathrm{a}}$, Alfonso Pedone ${ }^{\mathrm{b}}$, Cristina Siligardi ${ }^{\mathrm{a}}$ \\ a Department of Materials and Environmental Engineering, University of Modena and Reggio Emilia, via Vignolese 905, 41100, Modena, Italy \\ b Department of Chemistry, University of Modena and Reggio Emilia, via Campi 183, 41100, Modena, Italy
}

\section{A R T I C L E I N F O}

Article history:

Received 29 September 2010

Received in revised form 15 January 2011

Available online 28 February 2011

\section{Keywords:}

Molecular dynamics;

Vanadium;

Glasses

\begin{abstract}
A B S T R A C T
In this manuscript, classical molecular dynamics simulations (MD) have been applied to study the short and medium range order of very complex vanadium containing glasses with the aim of improving the first microscopic picture of such materials. A rigid ionic force-field has been extended to include the $\mathrm{V}^{5+}-\mathrm{O}, \mathrm{V}^{4+}-\mathrm{O}$ and $\mathrm{Cu}^{2+}-\mathrm{O}$ interatomic pair parameters and tested to reproduce structural properties of known crystal phases with quite good accuracy. Then the structure of $\mathrm{Na}_{2} \mathrm{O}-\mathrm{SiO}_{2}, \mathrm{CaO}-\mathrm{MgO}-\mathrm{Al}_{2} \mathrm{O}_{3}-\mathrm{SiO}_{2}$ and $\mathrm{Na}_{2} \mathrm{O}-\mathrm{P}_{2} \mathrm{O}_{5}$ glass compositions in which vanadium is present in the range 1-72 wt.\% (0.3-60 mol.\%) have been fully described in terms of vanadium local structure and Qn distributions. A fairly good agreement was found with experimental data further validating our computational models and providing a computational approach that could be used and extend to investigate in detail the structural information ( $\mathrm{V}-\mathrm{V}$ distances, $\mathrm{V}-\mathrm{O}-\mathrm{V}$ linkages and $\mathrm{BO} / \mathrm{NBO}$ ) directly correlated to macroscopic properties of application interest.
\end{abstract}

(c) 2011 Elsevier B.V. All rights reserved.

\section{Introduction}

In the last decades the modification of properties induced by the addition of transition metal (TM) oxides into glass matrix has been studied to explore the possibility to produce semiconductive glasses [1-9].

It is well know that TM oxides present an extremely rich variety of crystal phases and oxidation states of the metal ion and this leads to a complex scenario of possible properties useful for technological application such as magnetic recording, heterogeneous catalysis, insulators or semiconductors [10].

The glass systems studied until now are mainly borosilicate, borate, phosphate or tellurate glasses and it was observed that TM oxides impart peculiar electric, optical and magnetic properties to the final material. In particular the semiconducting nature of these glasses arises from the hopping of unpaired electrons between TM ions having multi valence states. The conduction process has been described by means of a polaron model in which the unpaired electron induces polarization around the TM ion $[11,12]$.

Among the TM ions, vanadium is a metal that exhibits a wide range of oxidation states (from 0 to +5 ), the most common being $+3,+4$ and +5 [13-17]. While $\mathrm{V}^{3+}$ occurs commonly in an octahedral symmetry, $\mathrm{V}^{4+}$ can be found in both the square pyramidal and octahedral configurations. Concerning $\mathrm{V}^{5+}$, it presents different kinds of symmetry: tetrahedral, square pyramidal and octahedral. The

\footnotetext{
* Corresponding author. Tel.: +39 0592056239; fax: +390592056243. E-mail address: guido.ori@unimore.it (G. Ori).
}

multiple oxidation states and the different symmetries assumed by vanadium confer to the glass a high complexity [18-21].

The structural and electronic properties of these glasses as well as their optical, magnetic and mechanical properties depend on the type and the concentration of the different valence state of the TM ion present as well as on the redox processes occurring in the melt at high temperature during the preparation [18-21]. A better knowledge of vanadium speciation (oxidation state and symmetry) as well as the characterization in detail of the glass structure is one of the key points for further elucidating and better understanding of the physical and chemical properties of vanadium containing materials [14].

In the last years, Electric Paramagnetic Resonance (EPR), XPS and Extended X-ray Adsorption Fine Structure (EXAFS) and X-ray Absorption near -edge structure (XANES) have been widely used to study the state of dissimilar TM ions in glasses as well as the interactions between unlike magnetic ions in disordered solid $[8,14,22-26]$ but for the vanadium oxide based glasses, the experimental studies appeared in literature showed promising but not conclusive results [12,27-31]. In the glass compositions previously studied vanadium was present as dopant $(<1 \mathrm{~mol} \%)$ or as the main constituent leading to vanadate glasses (> $40 \mathrm{~mol} \%$ ) [11,12]. The works reporting structural data of the vanadium containing glasses did not give any exhaustive information about the conductive properties of the system $\left(\left[\mathrm{V}_{2} \mathrm{O}_{5}\right]<1 \mathrm{~mol} \%\right)$, on the contrary, the system for which conductive properties are interesting and that have been analyzed in detail did not report specific structural information $\left(\left[\mathrm{V}_{2} \mathrm{O}_{5}\right]>20 \mathrm{~mol} \%\right)[11,12]$. Therefore, a detailed analysis of the structural modifications induced by the TM oxide on the glass network that could be correlated to macroscopical properties, such as conductivity, is still lacking. Moreover, recent studies have pointed out the importance of 
Table 1

Chemical compositions (wt.\%) of the selected glass systems (in brackets the molar compositions used in MD sim).

\begin{tabular}{|c|c|c|c|c|c|c|c|}
\hline System & $\mathrm{SiO}_{2}$ & $\mathrm{P}_{2} \mathrm{O}_{5}$ & $\mathrm{Al}_{2} \mathrm{O}_{3}$ & $\mathrm{Na}_{2} \mathrm{O}$ & $\mathrm{CaO}$ & $\mathrm{MgO}$ & $\mathrm{V}_{2} \mathrm{O}_{5} / \mathrm{VO}_{2}$ \\
\hline DIAN-1.0 & $48.55(50.44)$ & - & $20.32(12.44)$ & - & $22.72(25.29)$ & $7.43(11.50)$ & $0.98 / 0.00(0.34)$ \\
\hline DIAN-5.0 & $46.88(50.07)$ & - & $19.41(12.22)$ & - & $21.47(24.57)$ & $7.13(11.35)$ & $5.11 / 0.00(1.80)$ \\
\hline DIAN-50 & $24.66(38.02)$ & - & $10.83(9.84)$ & - & $11.10(18.35)$ & $3.68(8.46)$ & $49.73 / 0.00(25.33)$ \\
\hline NS2-1.0 & $68.17(69.30)$ & - & - & $30.80(30.35)$ & - & - & $1.03 / 0.00(0.35)$ \\
\hline NP-60 & - & $20.04(20.00)$ & - & $8.75(20.00)$ & - & - & $66.33 / 4.88(51.67 / 8.33)$ \\
\hline
\end{tabular}

quantification of the non-bridging oxygens (NBO) and V-V distances in the glass structure, considering that hopping conduction can occur primarily through vanadium ions along $\mathrm{V}-\mathrm{O}-\mathrm{V}$ linkages $[11,12,27,28]$ : It is well known that Molecular Dynamics (MD), providing mechanistic insights into the structure of the material, can be successfully used as a complementary tool to the experimental analysis to quantify these structural information in order both to complete the data resulting by experimental characterization and to correlate the structural features of the glasses to the properties shown by the materials [32-35].

Unfortunately, most of MD simulations have been applied to study the structure, transport and mechanical properties of alkaline-, [36-45] alkaline-earth [46] and phospho-silicate glasses [47-56] but only a few of them were devoted to glasses doped by TM ions and V-containing glasses [57,58].

In this work a computational procedure, based on classical molecular dynamics simulation, and specific potential parameters have been optimized in order to investigate in detail the structure of different vanadium containing glasses. The glass compositions analyzed range from systems with low vanadium oxide content $\left(\mathrm{V}_{2} \mathrm{O}_{5}\right.$ : 1-5 wt.\%) up to formulations containing higher amount of total vanadium oxide $\left(\left(\mathrm{V}_{2} \mathrm{O}_{5}+\mathrm{VO}_{2}\right): 50-70 \mathrm{wt} . \%\right)$. The first glasses were chosen because the detailed experimental characterization performed by Giuli et al. [17] on these systems allowed the validation of the computational procedure considered in this work. The high vanadium containing glasses were investigated in order to probe the computational procedure on systems with interesting conductive properties useful for potentially technological applications. In Table 1 are reported the compositions analyzed: DIAN-1, DIAN-5 and NS2-1 are multi-component glasses, in which vanadium is present in the range 1-5 wt.\%, characterized by a well-defined structural characterization which allows us to set up and to validate the MD computational procedure used for modeling the behavior of $\mathrm{V}^{5+}$ in glass systems; DIAN-50 has been considered in order to investigate the effect of an higher amount of $\mathrm{V}_{2} \mathrm{O}_{5}$ on the DIAN series; finally NP-60 has been simulated in order to test the computational procedure on a composition of application interest which also considers $\mathrm{V}^{4+}$ (for which an optimization of the potential parameters has been performed). Detailed description, in terms of number of atoms, of the specific composition for all the systems studied can be found in the Electronic Supplementary Information (ESI, S1). For the simulation of NP-60 system we used a $V^{+4} / V_{\text {tot }} \%$ of 7.5 , in accordance with the value extrapolated from the work of Tricot et al. [19].

The structural models generated have been analyzed in terms of the local site of the vanadium, its coordination, short range environment and medium range order in the glass network. The

Table 2

Input data (compositions, Priven-derived densities, number of atoms, and cell sizes) for the modeled glasses.

\begin{tabular}{llll}
\hline System & Density $\left(\mathrm{g} / \mathrm{cm}^{3}\right)$ & Atom number & Cell size $\left(\AA^{3}\right)$ \\
\hline DIAN-1.0 & 2.621 & 4303 & 38.8492 \\
DIAN-5.0 & 2.674 & 4430 & 38.8855 \\
DIAN-50 & 2.826 & 4147 & 38.5500 \\
NS2-1.0 & 2.474 & 4349 & 39.1441 \\
NP-60 & 2.882 & 3689 & 36.7100 \\
\hline
\end{tabular}

compositional effect as well as the presence of different modifier cations has been studied as a function of the vanadium content in the glass formulation. The structural information obtained have been compared with available experimental data and discussed in relation to the chemical and physical properties of these glasses.

\section{Materials and methods}

\subsection{Simulation details}

Molecular dynamics (MD) simulation is a powerful technique able to yield detailed information on glass structure but its success depends on a lot of factors [32]. Among these, the reliability of the interatomic potentials, the simulation methodology, and the simulation box size play fundamental roles. The number of atoms in the simulation box is a very important factor to define the dopant related structural information with high statistical meaning. On these grounds, the selected systems represent a really good opportunity on which to develop and validate a MD procedure, because they are some of the systems for which useful structural information are known with the higher relative amount of $\mathrm{V}$ content [59]. This is a crucial point because, for our knowledge, no structural information are available for glasses containing high concentration of TM ions that have shown encouraging results in terms of functional properties.

Based on the computational procedure proposed by Afify et al., [59] in this work, five different random configurations of each system containing a range of vanadium from 1.0 to $71.0 \mathrm{wt} . \%$ (0.3-60 mol\%) have been used. This procedure allows the possibility to evaluate the statistical significance of the obtained results. DIAN-1.0, DIAN-5.0 and NS2-1.0 compositions have been selected from Giuli et al. [17], NP-60 from Tricot et al. [19] and DIAN-50 has been selected as an extension of the DIAN series.

The initial configurations were generated by placing randomly $\sim 4000$ atoms in a cubic box. Atomic compositions and size length of the simulation boxes are reported in Table 2, together with the glass densities at room temperature calculated according to the Priven's empirical method [60] implemented in the SciGlass software [61].

The interatomic potential developed by Pedone et al., [62] is used, which however lacks for $\mathrm{V}-\mathrm{O}$ pair potential parameters. This forcefield uses partial atomic charges consistent with a charge of $-1.2 e$ for the oxygen ion, silicon has a charge of $+2.4 e$ while penta-valent vanadium has a charge of $+3.0 e$ and $+2.4 e$ for four-valent vanadium. The parameters were obtained (Table 3 ) using a well-validated refinement procedure, also recently re-proposed by Afify et al., [54] that basically consist in a combination of "conventional" and "relaxed"

Table 3

Morse interatomic potential parameters for the $\mathrm{Cu}^{+1.2}-\mathrm{O}^{-1.2}, \mathrm{~V}^{+3}-\mathrm{O}^{-1.2}$ and $\mathrm{V}^{+2.4}-\mathrm{O}^{-1.2}$ atomic pairs.

\begin{tabular}{lllll}
\hline Pair & $\begin{array}{l}D_{i j} \\
(\mathrm{eV})\end{array}$ & $\begin{array}{l}a_{i j} \\
\left(\AA^{-2}\right)\end{array}$ & $\begin{array}{l}r_{0} \\
(\AA)\end{array}$ & $\begin{array}{l}C_{i j} \\
(\mathrm{eV} \AA)\end{array}$ \\
\hline $\mathrm{Cu}^{+1.2}-\mathrm{O}^{-1.2}$ & 0.011856 & 1.643080 & 3.065264 & 3.0 \\
$\mathrm{~V}^{+3}-\mathrm{O}^{-1.2}$ & 0.021911 & 1.495955 & 3.398507 & 1.0 \\
$\mathrm{~V}^{+2.4}-\mathrm{O}^{-1.2}$ & 0.032832 & 2.109308 & 2.663618 & 1.0 \\
\hline
\end{tabular}


Table 4

Results obtained from the parameterization step.

\begin{tabular}{llllll}
\hline \multicolumn{6}{l}{ Averaged interatomic distances $(\AA)$} \\
\hline Crystal & $\mathrm{CN}-\mathrm{VS}$ & Pair & Obs. ${ }^{\mathrm{a}, \mathrm{b}}$ & Calc. & \multicolumn{1}{c}{ Diff. } \\
\hline $\mathrm{V}_{2} \mathrm{O}_{5}$ & {$[5] \mathrm{V}^{+3}$} & $\mathrm{~V}^{+3}-\mathrm{O}^{-1.2}$ & $1.819^{\mathrm{b}, \mathrm{c}}$ & 1.880 & -0.062 \\
$\mathrm{LiV}_{2} \mathrm{O}_{5}$ & {$[5] \mathrm{V}^{+3}-[5] \mathrm{V}^{+2.4}$} & $\mathrm{~V}^{+3}-\mathrm{O}^{-1.2}$ & $1.817^{\mathrm{b}, \mathrm{d}}$ & 1.800 & 0.017 \\
& & $\mathrm{~V}^{+2.4}-\mathrm{O}^{-1.2}$ & $1.902^{\mathrm{b}, \mathrm{d}}$ & 1.904 & -0.002 \\
$\mathrm{~V}_{6} \mathrm{O}_{13}$ & {$[6] \mathrm{V}^{+3}-[6] \mathrm{V}^{+2.4}$} & $\mathrm{~V}^{+3}-\mathrm{O}^{-1.2}$ & $1.923^{\mathrm{e}}$ & 1.992 & -0.069 \\
& & $\mathrm{~V}^{+2.4}-\mathrm{O}^{-1.2}$ & $1.936^{\mathrm{e}}$ & 2.133 & -0.197 \\
$\alpha-\mathrm{NaVO}_{3}$ & {$[4] \mathrm{V}^{+3}$} & $\mathrm{~V}^{+3}-\mathrm{O}^{-1.2}$ & $1.723^{\mathrm{f}}$ & 1.718 & 0.004 \\
$\mathrm{VO}_{2}$ & {$[6] \mathrm{V}^{+2.4}$} & $\mathrm{~V}^{+2.4}-\mathrm{O}^{-1.2}$ & $2.004^{\mathrm{g}}$ & 1.949 & 0.055 \\
$\mathrm{VP}_{2} \mathrm{O}_{7}$ & {$[6] \mathrm{V}^{+2.4}$} & $\mathrm{~V}^{+2.4}-\mathrm{O}^{-1.2}$ & $1.911^{\mathrm{b}}$ & 1.948 & -0.037 \\
$\alpha-\mathrm{Cu}_{2} \mathrm{~V}_{2} \mathrm{O}_{7}$ & {$[4] \mathrm{V}^{+3}$} & $\mathrm{~V}^{+3}-\mathrm{O}^{-1.2}$ & $1.709^{\mathrm{h}}$ & 1.726 & -0.017 \\
$\mathrm{CuO}$ & {$[5] \mathrm{Cu}^{+1.2}$} & $\mathrm{Cu}^{+1.2}-\mathrm{O}^{-1.2}$ & $2.058^{\mathrm{h}}$ & 2.130 & -0.072 \\
$\mathrm{Cu}_{4} \mathrm{O}_{3}$ & {$[6] \mathrm{Cu}^{+1.2}$} & $\mathrm{Cu}^{+1.2}-\mathrm{O}^{-1.2}$ & $2.232^{\mathrm{i}}$ & 2.224 & 0.008 \\
& {$[4] \mathrm{Cu}^{+1.2}$} & $\mathrm{Cu}^{+1.2}-\mathrm{O}^{-1.2}$ & $1.941^{\mathrm{j}}$ & 1.921 & 0.020 \\
& {$[2] \mathrm{Cu}^{+0.6}$} & $\mathrm{Cu}^{+0.6}-\mathrm{O}^{-1.2}$ & $1.867^{\mathrm{j}}$ & 1.842 & 0.025 \\
\hline
\end{tabular}

$$
\begin{array}{cl}
\text { a } & \text { Ref. [71]. } \\
\text { b } & \text { Ref. [72]. } \\
\text { c } & \text { Ref. [73]. } \\
\text { d } & \text { Ref. [74]. } \\
\text { e } & \text { Ref. [57]. } \\
\text { f } & \text { Ref. [75]. } \\
\text { g } & \text { Ref. [76]. } \\
\text { h } & \text { Ref. [77]. } \\
\text { i } & \text { Ref. [78]. } \\
\text { j } & \text { Ref. [79]. } \\
&
\end{array}
$$

fitting steps carried out with the general utility lattice program GULP code [63]. The $\mathrm{V}^{+3.0}-\mathrm{O}^{-1.2}, \mathrm{~V}^{+2.4}-\mathrm{O}^{-1.2}$ potential parameters were varied until the crystal structures selected are well reproduced (Table 4). These structures were selected because contains the vanadium in several valence states and coordination forms, as well as the same form of vanadium $\left([4] \mathrm{V}^{5+}\right)$ that Giuli et al. [17] showed to be present in the glasses studied. Moreover, Pedone's potentials [62] also lack of $\mathrm{Cu}^{+1.2}-\mathrm{O}^{-1.2}$ parameters for $\alpha-\mathrm{Cu}_{2} \mathrm{~V}_{2} \mathrm{O}_{7}$ and these were parameterized considering the crystal structures of $\mathrm{CuO}$ and $\mathrm{Cu}_{4} \mathrm{O}_{3}$. The fitted parameters are reported in Table 3 while the parameters for the remaining pairs were taken from Ref. [62].

The geometrical parameters of the different vanadium containing structures optimized by using the new parameters are compared to the experimental one in Table 4. This shows that the $\mathrm{V}-\mathrm{O}$ and $\mathrm{Cu}-\mathrm{O}$ distances are well reproduced with differences mainly less than $0.07 \AA$ which is satisfying due to the simplicity of the force-field used. The structures which showed higher difficulties to be reproduced are those which are characterized by a particular layering structure (as $\left.\mathrm{V}_{6} \mathrm{O}_{13}\right)$ and also containing vanadyl bond $\left(\mathrm{V}=\mathrm{O}\right.$, as $\left.\mathrm{V}_{2} \mathrm{O}_{5}\right)$, that probably need more ad-hoc complex potential forms. The DL_POLY package (Ver. 2.12) was employed for MD simulations [64]. Integration of the equations of motion was performed using the

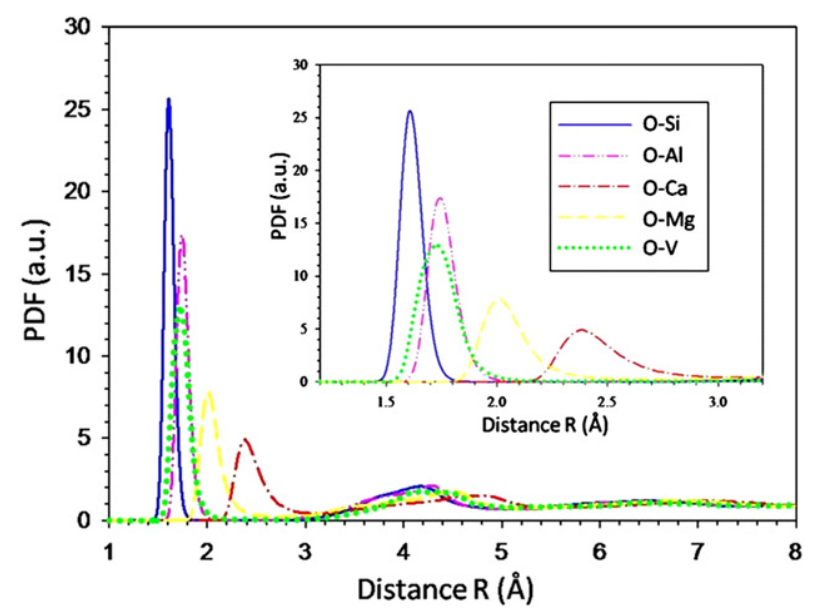

Fig. 1. Pair distribution functions $\mathrm{M}-\mathrm{O}$ of DIAN-5.0.
Verlet Leapfrog algorithm with a time step of $2 \mathrm{fs}$. Coulombic interactions were calculated by the Ewald summation method with a cutoff of $12 \AA$ and an accuracy of $10^{-4}$. A cutoff of $5.5 \AA$ has been used for the short range interactions. Similar conditions have been already validated and tested with success on different inorganic glass systems $[36,46]$.

Similarly to previous works $[32-35,65,66]$ that employed a rigid ionic model with partial charges, the system was heated at $5000 \mathrm{~K}$, a temperature more than adequate to bring the system to its liquid state in the framework of the adopted force-field [67-70]. The melt was then equilibrated for $100 \mathrm{ps}$ and subsequently cooled continuously from 5000 to $300 \mathrm{~K}$ in 1060 ps with a nominal cooling rate of $4.5 \mathrm{~K} / \mathrm{ps}$.

The temperature was decreased by $0.01 \mathrm{~K}$ every time step using a Berendsen thermostat with the time constant parameter for the frictional coefficient set to $0.4 \mathrm{ps}$. Another $100 \mathrm{ps}$ of relaxation at constant energy and $50 \mathrm{ps}$ of data production were performed at $300 \mathrm{~K}$. Configurations at every $0.1 \mathrm{ps}$ were recorded for structural analysis. The structural characterization of the glass materials have been obtained by the analysis of the pair distribution function PDF, coordination number distribution (CN) and bond angle distribution (BAD), derived by the statistical treatment of the data resulting from the MD simulations [32-35]. While the first parameter defines the averaged cation-oxygen bond length, directly comparable with the experimental data available for analogous systems, the second one permits the definition of the first coordination shell environment. This parameter, together with the $\mathrm{BAD}$, has been used to describe the cation-based polyhedra distortion as a function of the compositional changes [34].

The influence of both the vanadium content and of the extra cations such as $\mathrm{Al}^{3+}, \mathrm{Ca}^{2+}$ in DIAN systems or $\mathrm{Na}^{+}$in NS2 glasses have been investigated in terms of the bridging oxygen (BO), and nonbridging oxygen (NBO) distributions. Network former ion-oxygen bond distance criteria has been used to define the NBO and BO species: the NBO are oxygens linked to only one network former ion, and the BO are oxygens linked to two network former ions [34,35,64].

Changes in the medium range structure of the glasses as a function of the composition can be quantified by the $\mathrm{Q}^{\mathrm{n}}$ species distribution analysis. $A Q^{n}$ species is defined as a species with $n$ bridging oxygens linked to the network former cation. In this work the aluminum based $\mathrm{Q}^{\mathrm{n}}(\mathrm{Al})$ and the silicon based $\mathrm{Q}^{\mathrm{n}}(\mathrm{Si})$ distributions have been calculated [34,64].

\section{Results and discussions}

3.1. Short range order: bond lengths, coordination numbers and bond angle distributions

Insights on the short range order around the cations present in the glass structure has been obtained by the analysis of the PDFs curves, the ones calculated for the DIAN-5.0 glass have been plotted in Fig. 1 as an example.

The cations-oxygens average distances are listed in Table 5, these have been obtained by the position of the maximum of the first peak in the PDF curves and are in nicely agreement with those measured experimentally on similar glasses. The $\mathrm{V}-\mathrm{O}$ bond distances are in a very good agreement with those derived by Giuli et al [17]. In fact, the calculated $\mathrm{V}-\mathrm{O}$ bond distances ranges from $1.66 \AA$ for the NS2 to 1.71-1.72 Å for the DIAN samples and well compare to the experimental values of $1.697 \AA$ obtained for the composition analyzed and the value of 1.701 Å reported in literature for vanadinite [14].

A good agreement is also observed for the $\mathrm{V}-\mathrm{Si}$ distances derived from MD simulations (3.376, 3.379 and 3.421 Å for DIAN-1.0, DIAN-5.0 and NS2 respectively) and the experimental values of $3.4 \AA$ A reported by Giuli et al. [17].

Moreover, the $\mathrm{V}-\mathrm{O}$ and $\mathrm{V}-\mathrm{Si}$ distances are strongly dependent on the composition of the glasses; in particular, while a shorter $\mathrm{V}-\mathrm{O}$ bond 
Table 5

Averaged interatomic distances $\mathrm{R}(\AA)^{\mathrm{a}}$ characterizing the first peak of the pair distribution functions.

\begin{tabular}{|c|c|c|c|c|c|c|c|}
\hline \multicolumn{8}{|c|}{ Correlation $\mathrm{R}(\AA)^{\mathrm{a}}$} \\
\hline Sample & $\mathrm{O}-\mathrm{Si}(\mathrm{P})$ & $\mathrm{O}-\mathrm{Al}$ & $\mathrm{O}-\mathrm{V}^{5+} / \mathrm{V}^{4+}$ & $\mathrm{O}-\mathrm{Na}$ & $\mathrm{O}-\mathrm{Ca}$ & $\mathrm{O}-\mathrm{Mg}$ & $\overline{\mathrm{Si}(\mathrm{P})-\mathrm{V}^{5+} / \mathrm{V}^{4+}}$ \\
\hline DIAN-1.0 & $1.606(8)$ & $1.744(0)$ & $1.712(10)$ & - & $2.387(6)$ & $2.010(8)$ & $3.376(22)$ \\
\hline FWHM & 0.112 & 0.144 & 0.176 & & 0.304 & 0.224 & 0.224 \\
\hline DIAN-5.0 & $1.606(8)$ & $1.744(0)$ & $1.718(13)$ & - & $2.381(6)$ & $2.010(8)$ & $3.379(6)$ \\
\hline FWHM & 0.096 & 0.144 & 0.176 & & 0.288 & 0.224 & 0.208 \\
\hline DIAN-50 & $1.600(6)$ & $1.744(0)$ & $1.728(12)$ & - & $2.368(7)$ & $2.000(9)$ & $3.360(7)$ \\
\hline FWHM & 0.112 & 0.144 & 0.174 & & 0.265 & 0.232 & 0.215 \\
\hline NS2-1.0 & $1.616(0)$ & - & $1.662(16)$ & $2.328(8)$ & - & - & $3.421(15)$ \\
\hline FWHM & 0.112 & & 0.176 & 0.432 & & & 0.208 \\
\hline NP-60 & $1.52(0)$ & - & $1.776 / 1.744(11)$ & $2.352(9)$ & - & - & $3.456 / 3.296(9)$ \\
\hline FWHM & 0.104 & & $0.164 / 0.170$ & 0.350 & & & $0.198 / 0.210$ \\
\hline Lit. Exp. & $\begin{array}{c}1.63^{\mathrm{b}} \\
(1.52)^{\mathrm{b}}\end{array}$ & $1.75^{\mathrm{d}}$ & $1.697(20)^{\mathrm{f}}$ & $2.30-2.62^{\mathrm{g}}$ & $2.37-2.49^{\mathrm{i}}$ & $1.90-2.08^{1}$ & $3.400^{f}$ \\
\hline Theo. & $\begin{array}{c}1.59-1.62^{\mathrm{C}} \\
(1.53-1.55)^{\mathrm{c}}\end{array}$ & $1.70-1.82^{\mathrm{e}}$ & - & $2.31-2.46^{\mathrm{h}}$ & $2.28-2.37^{\mathrm{k}}$ & $2.01^{\mathrm{k}}$ & - \\
\hline
\end{tabular}

a Confident intervals for $95 \%$ of confident level of the last digit are given in parenthesis.

b Ref. [80] and [81].

c Ref. [36], Ref [46] and Ref [51].

d Ref. [82].

e Ref. [82], [83] and [84].

${ }^{f}$ Ref. [14] and [17].

g Ref. [85-87].

h Ref. [46,88].

${ }^{\mathrm{i}}$ Ref. [89] and [90].

${ }^{k}$ Ref. [46] and[51].

${ }^{1}$ Ref. [89] and [91].b, c, d, e, g, h, i, k and l were obtained from V-free glasses.

distance occurs into the NS2-1.0 sample (1.662 ̊̊), a quite larger V-O bond distances are observed in the DIAN samples (from 1.712 to $1.728 \AA$ ). The same is true for the $\mathrm{V}$-Si distances. These compositional effects are related to the structural changes, occurring into the vanadium local sites, induced by the presence of different cations into the glass network.

Along the DIAN series only a slightly effect of the vanadium concentration on the $\mathrm{V}-\mathrm{O}$ bond distance has been occurred suggesting however that, for these glasses, the vanadium content does not affect the local configuration of the vanadium local sites.

The NP-60 composition shows the higher V-O bond distances for both $\mathrm{V}^{+5}$ and $\mathrm{V}^{+4}$ compared to the DIAN and NS2 series, coherently to the experimental data showed by P-containing crystal structures (Table 4) that underlies the effect of different former ions ( $\mathrm{P}$ than $\mathrm{Si} / \mathrm{Al}$ ) on the local configuration of vanadium.

The analysis of the Si-O and V-O PDFs in terms of the NBO and BO contributions reported in Table 6 shows that while the V-NBO distance is quite similar for all the compositions, the $\mathrm{V}-\mathrm{BO}$ shows a lengthening passing from DIAN-1.0 (1.74 $\mathrm{A})$ to DIAN-5.0/-50 (1.76 $)$ and to NP-60 (1.79 $\mathrm{A})$ and NS2-1.0 (1.81 $\AA$ ).

Table 6

Averaged cation-NBO and -BO interatomic distances.

\begin{tabular}{lllllll}
\hline \multicolumn{6}{l}{ Correlation R $(\AA)^{\mathrm{a}}$} & \multicolumn{6}{l}{} \\
\hline & DIAN-1.0 & DIAN-5.0 & DIAN-50 & NS2-1.0 & NP-60 & Lit. \\
\hline Si(P)-NBO & 1.584 & 1.584 & 1.568 & 1.552 & 1.504 & $1.55-1.60[27]$ \\
& $(0)$ & $(0)$ & $(0)$ & $(0)$ & $(1)$ & \\
FWHM & 0.096 & 0.096 & 0.086 & 0.080 & 0.085 & \\
Si(P)-BO & 1.616 & 1.616 & 1.600 & 1.616 & 1.520 & $1.59-1.63[27]$ \\
& $(0)$ & $(0)$ & $(0)$ & $(6)$ & $(2)$ & \\
FWHM & 0.112 & 0.112 & 0.096 & 0.096 & 0.096 & \\
V-NBO & 1.664 & 1.664 & 1.664 & 1.664 & 1.648 & - \\
& $(19)$ & $(0)$ & $(0)$ & $(10)$ & $(1)$ & \\
FWHM & 0.128 & 0.128 & 0.096 & 0.128 & 0.96 & \\
V-BO & 1.744 & 1.760 & 1.760 & 1.808 & 1.792 & - \\
& $(21)$ & $(8)$ & $(6)$ & $(16)$ & $(6)$ & \\
FWHM & 0.176 & 0.176 & 0.128 & 0.192 & 0.144 & \\
\hline
\end{tabular}

a Confident intervals for $95 \%$ of confident level of the last digit are given in parenthesis.
The behaviour shown by NS2-1.0 sample could be explained in terms of a more depolymerised network induced by the $\mathrm{Na}^{+}$ions which can be also occurred in the NP-60 glass. This compositional effect, related to the different network modifiers present in the glass formulations, has been also observed in the $\mathrm{V}-\mathrm{O}$ bond distance which is lower for NS2-1.0 than that observed for the DIAN glasses. For the NP-60 sample the effect of a different network former ion has to be additionally taken into account. The short range structure has been also investigated by considering the distribution of the polyhedra constituted by the nearest oxygens surrounding the central cation. This information is codified by the coordination number $(\mathrm{CN})$ which is obtained by the integration of the cation-oxygens PDFs by using the following cutoff: $1.9 \AA$ for $\mathrm{Si}-\mathrm{O}, 1.9 \AA$ for $\mathrm{P}-\mathrm{O}, 2.1 \AA \AA$ for $\mathrm{Al}-\mathrm{O}, 3.1 \AA$ for $\mathrm{Na}-\mathrm{O}, 3.0 \AA$ for $\mathrm{Ca}-\mathrm{O}, 2.6 \AA$ for $\mathrm{Mg}-\mathrm{O}$ and $2.5 \AA$ for $\mathrm{V}-\mathrm{O}$ pairs. The cutoff of the first coordination shell is defined as the distance where the second derivative for each coordination plot becomes zero after the first peak in the PDF.

The averaged coordination number of the different species reported in Table 7 confirms the network former role of $\mathrm{Si}^{4+}, \mathrm{Al}^{3+}$ and $\mathrm{P}^{5+}$ ions, characterized by a four-fold coordination.

Moreover the Bond Angle Distribution (BAD) analysis of the $\mathrm{O}-\mathrm{Si}-\mathrm{O}$, $\mathrm{O}-\mathrm{P}-\mathrm{O}$ and $\mathrm{O}-\mathrm{Al}-\mathrm{O}$ shows a main peaks respectively at about $108^{\circ}, 109^{\circ}$ and $107^{\circ}$ (Table 8) confirming the tetrahedral configuration for all the cations, in agreement with a network former role played by these ions in the glass network.

It is worth noting that no significant changes in the $\mathrm{Si}^{4+}$ coordination, as well as in the $\mathrm{Al}^{3+}$, have been observed for the DIAN systems as a function of the vanadium concentration into the glass matrix.

On the contrary, small changes in the averaged $\mathrm{CN}$ of vanadium for the DIAN series can be noted as a function of the vanadium concentration. The averaged $\mathrm{CN}$ increases from 4.075 to 4.520 in the DIAN glasses, that reflects a higher oxygen coordination grade by vanadium ions in the DIAN-50 correlated to an higher percentage of penta- and octahedral vanadium than (with respect to) DIAN-1 and DIAN-5 glasses. These results support the hypothesis that a higher amount of vanadium in the DIAN series induces strong interconnection between the polyhedral resulting in a more polymerized glass network. These considerations are also supported by the higher averaged $\mathrm{CN}$ that shows the calcium in the DIAN-50. 
Table 7

Averaged coordination numbers.

\begin{tabular}{|c|c|c|c|c|c|c|}
\hline \multicolumn{7}{|l|}{$\mathrm{CN}_{\mathrm{avg}}{ }^{\mathrm{a}}$} \\
\hline & DIAN-1.0 & DIAN-5.0 & DIAN-50 & NS2-1.0 & NP-60 & Lit. \\
\hline $\mathrm{Si}(\mathrm{P})-\mathrm{O}$ & $4.000(0.1)$ & $4.000(0.2)$ & $4.000(0.1)$ & $4.000(0.1)$ & $4.000(0.1)$ & $3.9-4.0[27]$ \\
\hline $\mathrm{Al}-\mathrm{O}$ & $3.999(1)$ & $4.001(1)$ & $4.041(5)$ & - & - & $3.98-4.0[28]$ \\
\hline $\mathrm{V}^{5+}-\mathrm{O} / \mathrm{V}^{4+}$ & $4.163(60)$ & $4.075(12)$ & $4.520(8)$ & $4.31(12)$ & $5.131(10) / 4.626(53)$ & $4.0(4)[17]$ \\
\hline $\mathrm{Ca}-\mathrm{O}$ & $5.154(56)$ & $5.054(63)$ & $6.005(54)$ & - & - & $5-6[31,34$ \\
\hline $\mathrm{Mg}-\mathrm{O}$ & $4.087(48)$ & $4.061(57)$ & $4.404(64)$ & - & - & $4[31,34$ \\
\hline $\mathrm{Na}-\mathrm{O}$ & - & - & - & $5.056(17)$ & $6.445(35)$ & $4.0-6.0[32,33$ \\
\hline
\end{tabular}

a Confident intervals for $95 \%$ of confident level of the last digit are given in parenthesis.

Comparing the DIAN series with the NS2-1.0 sample a compositional effect on the local structure of the vanadium can be supposed. This behaviour can be explained considering the different role played by the network modifier present in the two class of glasses: the presence of $\mathrm{Na}^{+}$ ions in the NS2-1.0 glass induce a strong de-polymerization of the glass network resulting into the possibility of the vanadium ions to accommodate more oxygen ions in their first coordination shell. Conversely, the presence of aluminium in the DIAN glasses leads to more packed silicon and aluminium glass framework with smaller number of oxygen ions surrounding the $\mathrm{V}^{5+}$ site. Moreover the calcium present in the DIAN systems play a network modifier effect but it is well known that induce lower glass depolymerisation with respect to $\mathrm{Na}^{+}$ ions and this support the previous statements on vanadium $\mathrm{CN}$ distributions.

$\mathrm{NP}-60$ shows an averaged $\mathrm{CN}$ for the $\mathrm{V}^{5+}$ in quite good accordance with experimental solid-NMR data [19], that underline the tendency of $\mathrm{V}^{5+}$ to progressively change into five-fold coordination in systems containing higher amount of $\mathrm{V}\left([5] \mathrm{V}^{5+}\right)$. This composition, showing interesting properties for technological applications, is the subject of further systematic investigation in order to evaluate and quantify the effect of the concentration of vanadium on its local environment in phosphate glasses, [92] as delineated by solid-NMR investigation [19].

About the averaged $\mathrm{CN}$ of $\mathrm{V}^{4+}$ in relation to its paramagnetism character solid-NMR data can be obtained only for quite lower vanadium content $(<10 \%)$ containing glasses and for this reason no experimental data is available to validate the calculated averaged $\mathrm{CN}$ for NP-60 sample. The MD result describes $\mathrm{V}^{4+}$ in a distorted pentahedral coordination.

Further investigations of the compositional effect on the short range structure of these glasses can be done considering the $\mathrm{BO}$ and NBO distribution analysis. Ideally, pure $\mathrm{SiO}_{2}$ network is fully composed of corner shared $\mathrm{SiO}_{4}$ tetrahedral units [32]. The presence of extra cations in the glass composition leads to the presence of different rearrangement of the oxygen ions: oxygen bonded (BO) to the two network former ion $\left(\mathrm{Si}^{4+}\right.$ or $\mathrm{Al}^{3+}$ for DIAN/NS2 and $\mathrm{P}^{5+}$ for $\mathrm{NP}$ ) and oxygens bonded only to one network former (NBO). Fig. 2 shows that for all the samples the main contribution to the $\mathrm{Si}^{4+}$ coordination is ascribed to the BO species ( $80 \%)$ confirming its network former role. This holds also for $\mathrm{Al}^{3+}$ whose first coordination shell is constituted by a percentage higher than $80 \%$ of BO species as well as for $\mathrm{P}^{5+}$ into the NP-60 sample. It is also worth noting that in

Table 8

Averaged bond angle distributions.

\begin{tabular}{lllllll}
\hline${\text { BAD }(\mathrm{deg})^{\mathrm{a}}}^{\mathrm{a}}$ & \multicolumn{7}{l}{} \\
\hline & DIAN-1.0 & DIAN-5.0 & DIAN-50 & NS2-1.0 & NP-60 & Lit. \\
\hline O-Si(P)-0 & $108(0)$ & $108(0.5)$ & $108(0.5)$ & $109(0)$ & $109(0.5)$ & $107-110[27]$ \\
FWHM & 13 & 13 & 12 & 11 & 13 & $(108-110)[27]$ \\
O-Al-O & $107(0)$ & $107(0)$ & $107(0.5)$ & - & & $105-108[28]$ \\
FWHM & 18 & 18 & 13 & & & \\
\hline
\end{tabular}

a Confident intervals for $95 \%$ of confident level of the last digit are given in parenthesis. the DIAN glasses no significant changes occur in the BO and NBO distributions for DIAN-1.0 and DIAN-5.0 confirming the previous statement on the independency of the glass network on the vanadium content for systems in which its concentration is less than $~ 5 \mathrm{wt} . \%$ [17].

At higher vanadium content (DIAN-50), the difference between $\mathrm{V}-\mathrm{NBO}$ and $\mathrm{V}$-BO percentages is more evident, underlying the propensity of vanadium, in this concentration, to promote a more rigid glass network (Fig. 3). Moreover, the V-BO and V-NBO distributions show a consistent dependency on the glass composition: while for the NS2-1.0 glass the percentage of $\mathrm{BO}$ and $\mathrm{NBO}$ is quite similar (about $50 \%$ ) and no prevalence of $\mathrm{BO}$ or $\mathrm{NBO}$ contribution can be noted into the local site of vanadium, for the DIAN glasses the $\mathrm{BO}$ contribution is greater than the NBO one (about $60 / 80 \%$ vs $40 / 20 \%$ for DIAN-1-5.0/DIAN-50, respectively). This result confirms that the presence of $\mathrm{Al}^{3+}$ and $\mathrm{Ca}^{2+}$, in the DIAN systems, induces a glass structure in which the polyhedra are strongly interconnected to constitute the three dimensional network.

Stronger polymerized and rigid glass network has been induced by vanadium into the NP-60 system as resulting by the presence of $\sim 97 \%$ of $\mathrm{V}-\mathrm{BO}$ in the structure.

Trying to compensate the lack of structural information derived by the experimental characterization of these glasses, MD analysis has been especially focused on the study of the local environment of the vanadium ion. The definition of the existing relationship between composition, structural role of vanadium and the properties experimentally observed for these systems can be useful to the design and optimization of new glass formulation for technological application. With this aim the first coordination shell of the vanadium has been analysed in term of the contribution of the other cations present in the glass formulation.

Figs. 4 and 5 show the percentage of the cations present in the local site of the vanadium for the DIAN NS2 and NP glass systems, obtained by the integration of the PDF first peak of the $\mathrm{M}-\mathrm{V}$ pairs $(\mathrm{M}=\mathrm{Si}, \mathrm{Al}, \mathrm{Ca}$ and Mg DIAN; Si, Na for NS2-1.0; P and Na for NP-60), normalized with respect to the number of $\mathrm{V}$ atoms and compared to $100 \%$. Along the

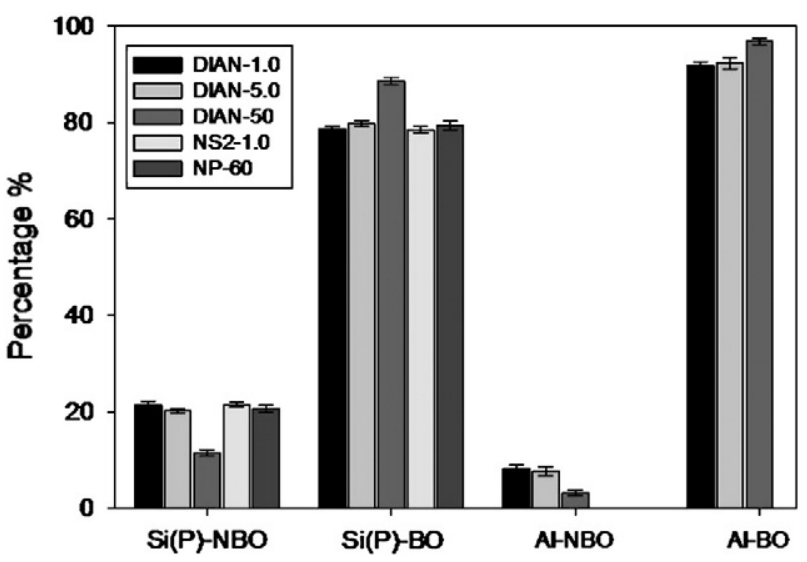

Fig. 2. NBO- and BO-distributions of $\mathrm{Si}$ and $\mathrm{Al}$. 


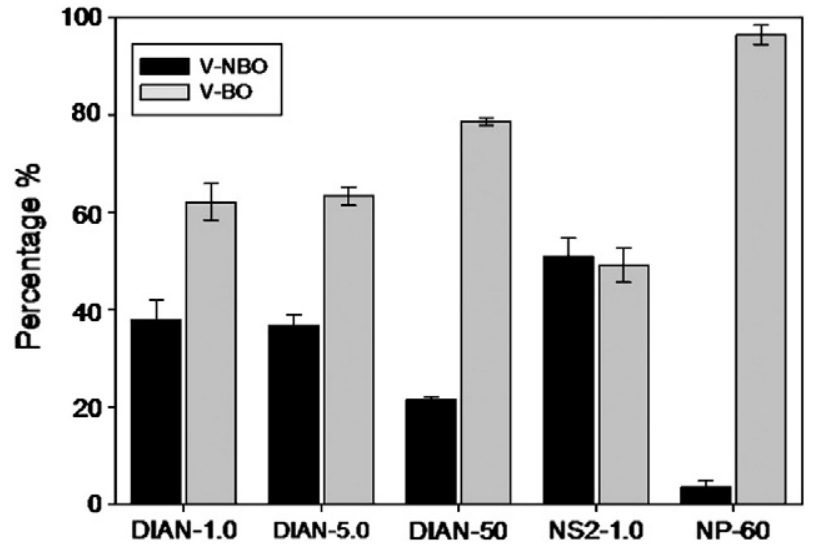

Fig. 3. NBO- and BO-distributions of V.

DIAN series can be noted an evident change in terms of the different element repartition between the low-vanadium content samples and the higher vanadium content samples. For DIAN-1.0 and DIAN-5.0 the main contribution to the vanadium local site is ascribed to the $\mathrm{Ca}^{2+}$ ions for about $40 \%$, that is substituted by the contribution ascribed by the $\mathrm{V}^{5+}$ ions in DIAN-50 ( 33\%), supporting that increasing concentration of vanadium in the glass promotes the accommodation of other $\mathrm{V}^{5+}$ ions into the vanadium first coordination shell. These results could be explained considering the possibility of vanadium to cluster into the glass matrix as results of the increasing concentration of $\mathrm{V}_{2} \mathrm{O}_{5}$ in the glass formulation. Comparing the DIAN systems to the NS2-1.0 it becomes evident that the contribution of the $\mathrm{Si}^{4+}$ to the $\mathrm{V}^{5+}$ first coordination shell decrease to the $20 \%$ and this could be related to the stronger modifier effect of the $\mathrm{Na}^{+}$(that contributes for the $80 \%$ to the $\mathrm{V}^{5+}$ coord. shell) with respect to $\mathrm{Ca}^{2+}$ and resulting to a more open glass network of the NS2-1.0 glass. NP-60 shows a value of $~ 78 \%$ of contribution ascribed by other $\mathrm{V}$ ions (both $\mathrm{V}^{5+}$ and $\mathrm{V}^{4+}$ ) to the $\mathrm{V}$ coord. shell, proving the formation of a sort of continuous framework of vanadium centred polyhedra $\left(\mathrm{VO}_{\mathrm{x}}\right)$ in the glass system, that can be considered a key factor in order to show interesting properties (electron conduction...) of potential application.

Further details of the local structure of vanadium can be derived by the BAD of the $\mathrm{O}-\mathrm{V}-\mathrm{O}$ species derived by the MD analysis.

Fig. 6 shows an interesting trend in which beside the main peak at about $109^{\circ}$ corresponding to a tetrahedral configuration related to the four-fold coordination of the $\mathrm{V}^{5+}$, another peak at about $90^{\circ}$ is observed. The intensity of the peak increases going from the DIAN-5.0 to DIAN-50 for which the peak becomes extremely defined. This is associated to a five-fold coordination of the vanadium that result greater in the DIANsystem with higher vanadium content. Also NS2-1.0 shows a second

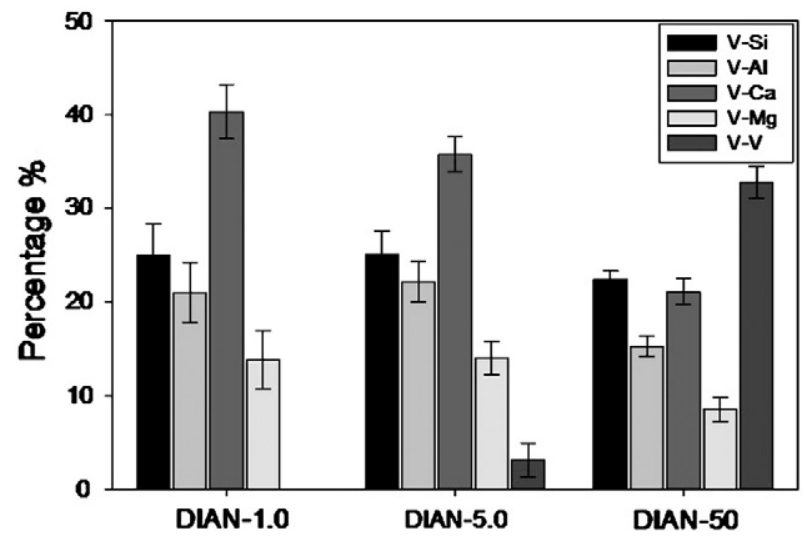

Fig. 4. Percentage of cations present in the local site of vanadium for DIAN series.

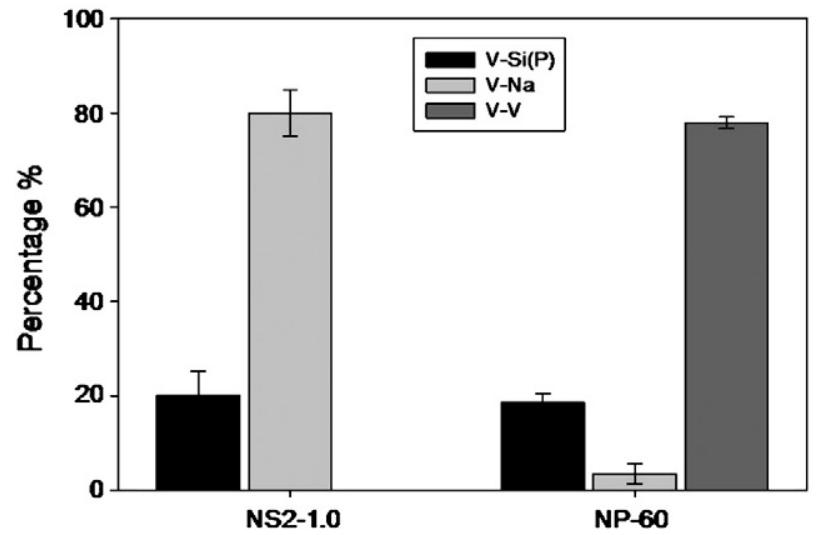

Fig. 5. Percentage of cations present in the local site of vanadium for NS2 and NP-60 samples.

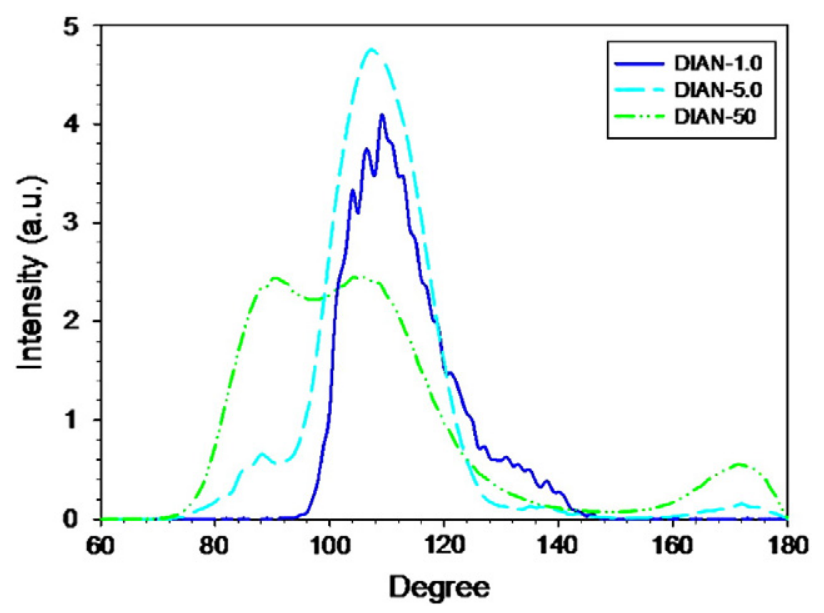

Fig. 6. Bond angle distributions $\mathrm{O}-\mathrm{V}-\mathrm{O}$ for the DIAN series.

defined peak at $90^{\circ}$ and this can be explained considering that the NS2-1.0 glass network results more depolymerised allowing the accommodation of more oxygen ions in the first coordination shell of the vanadium ions (Fig. 7). NP-60 glass shows a $\mathrm{O}-\mathrm{V}^{4+}-\mathrm{O}$ centred at $90^{\circ}$ that can infer to square pyramidal $\left(\mathrm{VO}_{5}\right)$ and octahedral $\left(\mathrm{VO}_{6}\right)$ geometry. $\mathrm{O}-\mathrm{V}^{5+}-\mathrm{O}$ shows double peaks, as DIAN-50, proving the co-existence of $\mathrm{V}^{5+}$ in four- and penta- and/or hesa-coordinated, in accordance with experimental results [19] and similar to previous MD study performed on pure $\mathrm{V}_{2} \mathrm{O}_{5}$ glass (Fig. 7) [58].

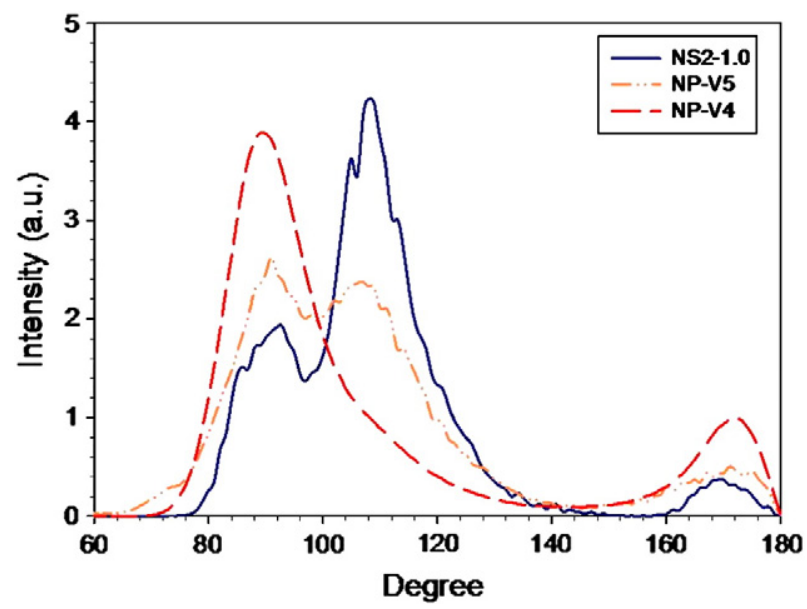

Fig. 7. Bond angle distributions $\mathrm{O}-\mathrm{V}-\mathrm{O}$ for NS2-1.0 and NP-60 sample. 


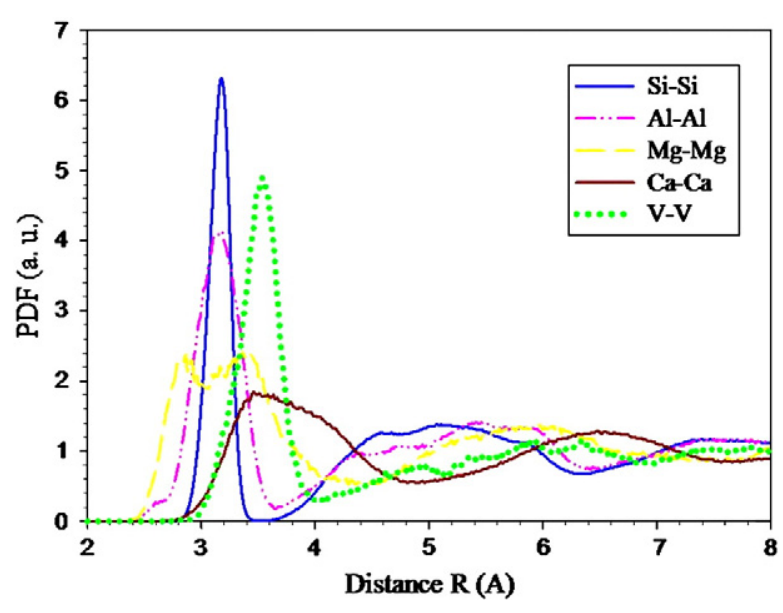

Fig. 8. M-M pair distribution functions of DIAN-5.0.

\subsection{Medium range order and $Q$ n distributions}

A first evaluation of the possible clustering of vanadium ions have been obtained, in first attempts, by the analysis of cation-cation PDFs. $\mathrm{Si}-\mathrm{Si}, \mathrm{Al}-\mathrm{Al}, \mathrm{Mg}-\mathrm{Mg}$ and $\mathrm{Ca}-\mathrm{Ca}$ distribution functions show profiles closed to data already reported in literature (see Fig. 8 as example). "Si-Si presents the first peak in the range of 3.15-3.18 $\AA$ for the DIAN series closed to the 3.02-3.16 reported in literature [46,50,54]. Al-Al shows the first peak in the range of 3.08-3.18 $\AA$ (in the range of literature values [83]) and a bump between at 2.5 and $2.8 \AA$, probably due to the effect of the presence of discrete percentages of $\mathrm{Ca}^{+2}$ and $\mathrm{Mg}^{+2}$ ions which can constrain the $\mathrm{Al}$ atoms to be closer, in view of their field strength.

Ca-Ca distribution function shows a first pdf peak at $3.5 \AA$ while Mg-Mg pdf shows a doublet maxima around 2.8 and $3.3 \AA$, for all the DIAN sample. As previously reported and discussed by Pedone et al. [46] this doublet peak is due to two-membered rings of $\mathrm{Mg}$ and to $\mathrm{Mg}-\mathrm{O}-\mathrm{Mg}$ bridges formed by $\mathrm{MgO}_{4}$ tetrahedra in the glass network."

Along the DIAN series, only DIAN-5.0 and DIAN-50 show a defined V-V peak, centred at $3.65 \AA$ and $3.60 \AA$, respectively, suggesting an evident structuring of this distribution (Fig. 8). The lack of a well-defined $\mathrm{V}-\mathrm{V}$ peak for DIAN-1.0 and NS2-1.0 can be related to the low concentration $\mathrm{V}^{5+}$ ions in the glass systems. NP-60 shows defined $\mathrm{V}^{5+}-\mathrm{V}^{5+}, \mathrm{V}^{4+}-\mathrm{V}^{4+}$ and $\mathrm{V}^{4+}-\mathrm{V}^{5+}$ peaks at $3.63 \AA$, $3.41 \AA$ and $3.44 \AA$ respectively. These values are well correlated with $\mathrm{V}-\mathrm{V}$ values reported in literature obtained both experimentally and computationally [12,58]. Fig. 9 gives a visual demonstration of the structuring of the $\mathrm{VO}_{\mathrm{x}}$ polyhedra network along the DIAN series. Analysing T-O-T linkages (Table 9) it can be noted that for DIAN series only for DIAN-5.0 and DIAN-50 significant statistical values of $\mathrm{Si}-\mathrm{O}-\mathrm{V}, \mathrm{Al}-\mathrm{O}-\mathrm{V}$ and $\mathrm{V}-\mathrm{O}-\mathrm{V}$ have been obtained, as a further evidence of the importance of the concentration of $\mathrm{V}^{5+}$ for this analysis.

Furthermore, in relation to the Loewenstein's aluminium avoidance principle [93], for DIAN-1.0 and DIAN-5.0 quite surprising high amounts (43.09\% and $40.91 \%$, respectively) of Al-O-Al linkages can be noted respect to $\mathrm{Si}-\mathrm{O}-\mathrm{Si}$ and $\mathrm{Si}-\mathrm{O}-\mathrm{Al}$, considering that $\mathrm{Al}-\mathrm{O}-\mathrm{Al}$ linkages should be energetically less favourable than $\mathrm{Si}-\mathrm{O}-\mathrm{Al}$. So far, numerous experimental and theoretical studies have already proved and demonstrated the possibility to violate the "aluminium avoidance" rule in view of different motivations [94-101]. In particular Cormier et al. ${ }^{[102]}$ justified, by MD simulations, this violation for $\mathrm{SiO}-\mathrm{Al}_{2} \mathrm{O}_{3}-\mathrm{CaO}$ with $\mathrm{R}=\mathrm{CaO} / \mathrm{Al}_{2} \mathrm{O}_{3}=1.57$ in view of the effect due to the field strength of $\mathrm{Ca}^{+2}$ which induces a lower enthalpy of ordering and promotes the formation of Al-O-Al linkages. Our results are consistent with Cormier et al. considering that DIAN-1.0 and DIAN-5.0 show higher R values $(\sim 3.0)$, considering that also $\mathrm{Mg}^{2+}$ promotes the constraining of $\mathrm{Al}$ atoms to be closer and to form $\mathrm{Al}-\mathrm{O}-\mathrm{Al}$ linkages $\left(\mathrm{Mg}^{+2}\right.$ present a field strength higher than $\mathrm{Ca}^{+2}$ ). DIAN-50 shows a value of Al-O-Al linkages (3.95\%) respect to $\mathrm{Si}-\mathrm{O}-\mathrm{Al}(14.74 \%)$ and $\mathrm{V}-\mathrm{O}-\mathrm{Al}$ (18.37\%) consistent with the "aluminium avoidance" rule, however for this system (high V content) further studies are needed to understand the effect of vanadium oxide on $\mathrm{Al}-\mathrm{O}-\mathrm{Al}$ linkages.

NP-60 glass shows a total $~ 64 \%$ of $\mathrm{V}-\mathrm{O}-\mathrm{V}$ linkages, supporting the observations previously discussed that proved the formation of a $\mathrm{VO}_{\mathrm{x}}$ continuous framework in this glass. The low percentage of $\mathrm{P}-\mathrm{O}-\mathrm{P}$ linkages, in agreement with a $\sim 90 \%$ of $\mathrm{Q}^{0}$ sites for $\mathrm{P}$ obtained from simulations, is in greatly accordance with experimental evidences, demonstrating the isolation of phosphate groups in the vanadate network in systems with high $\mathrm{V}_{2} \mathrm{O}_{5}$ content [19]. This analysis underlined also the potential usefulness of this computational approach in order to quantify structural information $\left(\mathrm{V}^{+5}-\mathrm{O}-\mathrm{V}^{+4}\right.$ link) that can be directly correlated to peculiar properties of application interest (see snapshot in Fig. 9) [92].

Information on the intermediate range order of the glasses can be obtained by the $\mathrm{Q}^{\mathrm{n}}$ species distribution analysis. The $\mathrm{Q}^{\mathrm{n}}$, defined as a specie in which $\mathrm{n}$ BOs are directly linked to the network former ion, is related to the mutual interactions between the silicon based tetrahedra and gives information about the degree of polymerization of the polyhedra into the three dimensional network.

It is well known that the contributions to the silicon coordination derive by the presence of $\mathrm{NBO}$ or $\mathrm{BO}$ species in the $\mathrm{Si}^{4+}$ first coordination shell and the percentage of the different contributions is related to the other ions present in the glass matrix.

The structure of vitreous silica is constituted only by $Q^{4}$ species and the addition of network modifier in the composition promotes the depolymerisation of the structure with an increase of the NBO contribution to the silicon coordination and a consequently $\mathrm{Q}^{\mathrm{n}}$ distribution shifts to $\mathrm{Q}^{\mathrm{n}}$ speciation with lower $\mathrm{n}$ (Fig. 10).

DIAN compositions show the prevalence of $Q^{3}$ and $Q^{4}$ species for the $\mathrm{Si}^{4+}$ supporting the network former role played by the silicon in these glasses, in agreement with the NBO and BO distribution already discussed (Fig. 2). As concerning the intermediate range order, samples considered in this work show a significant dependence of the network interconnection as a function of the glass composition. In particular the presence of different network modifiers in the glass formulation affects the $Q^{\text {n }}$ distribution: the NS2-1.0 shows a ratio $Q^{\mathrm{x}}=\mathrm{Q} 4 /\left(\mathrm{Q}^{3}+\mathrm{Q}^{2}+\mathrm{Q}^{1}+\mathrm{Q}^{0}\right)$ of 0.5 that is lower than the values obtained for the DIANs systems $(0.62$, 0.68 and 1.75 for DIAN-1, DIAN-5 and DIAN-50 respectively) suggesting a more depolymerised glass network resulting from the presence of $\mathrm{Na}^{+}$ as network modifier in the glass. DIAN-50 shows an increment of $\mathrm{Q}^{4}$

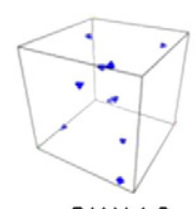

DIAN-1.0

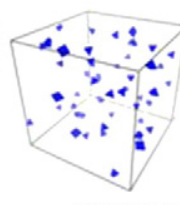

DIAN-5.0

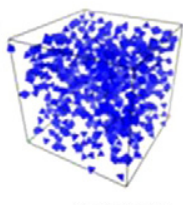

DIAN-50

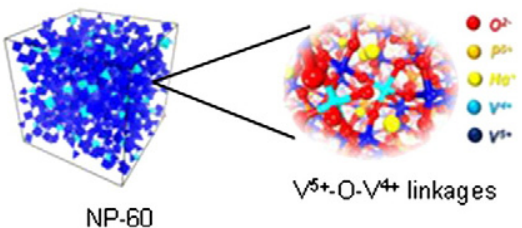

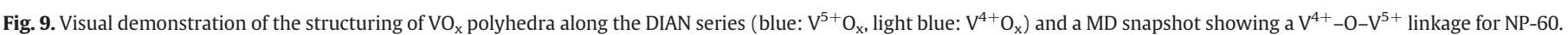


Table 9

Averaged percentage of T-O-T linkages.

\begin{tabular}{|c|c|c|c|c|c|c|}
\hline & $\mathrm{Si}(\mathrm{P})-\mathrm{O}-\mathrm{Si}(\mathrm{P})$ & $\mathrm{Al}-\mathrm{O}-\mathrm{Al}$ & Si-O-Al & $\mathrm{Si}(\mathrm{P})-\mathrm{O}-\mathrm{V}^{+5} / \mathrm{P}-\mathrm{O}-\mathrm{V}^{+4}$ & Al-O-V & $\mathrm{V}^{+5}-\mathrm{O}-\mathrm{V}^{+5} / \mathrm{V}^{+5}-\mathrm{O}-\mathrm{V}^{+4} / \mathrm{V}^{+4}-\mathrm{O}-\mathrm{V}^{+4}$ \\
\hline DIAN-1.0 & $46.94(0.23)$ & $43.09(0.63)$ & $8.69(0.66)$ & $0.82(0.17)$ & $0.46(0.08)$ & $0(0)$ \\
\hline DIAN-5.0 & $44.72(0.59)$ & $40.91(1.29)$ & $7.44(0.49)$ & $4.30(0.18)$ & $2.54(0.38)$ & $0.09(0.04)$ \\
\hline DIAN-50 & $11.63(0.31)$ & $3.95(0.85)$ & $14.74(0.54)$ & $28.93(0.19)$ & $18.37(0.15 \mathrm{CI})$ & $22.37(0.14)$ \\
\hline NS2-1.0 & $98.93(0.14)$ & - & - & $1.07(0.13)$ & - & $0(0)$ \\
\hline NP-60 & $0.58(0.10)$ & - & - & $33.67(0.22) / 1.84(0.38)$ & - & $59.83(0.09) / 3.98(0.11) / 0.10(0.04)$ \\
\hline
\end{tabular}

Confident intervals for $95 \%$ of confident level of the last digit are given in parenthesis.

contribution up to $\sim 63 \%$, demonstrating an increment of the crosslinking grade of this glass, in accordance with previous statements.

The evident difference between DIAN and NS2 series can be explained considering that $\mathrm{Ca}^{2+}$ ions present in the DIANs act as modifier but compared to the $\mathrm{Na}^{+}$ions lead to a more packed structure and increase the cohesion energy of the glass. Moreover, the $\mathrm{Mg}^{2+}$ ions present together with $\mathrm{Ca}^{2+}$ into the DIAN systems form Si-O-Mg chains of tetrahedra and act as a pseudo-network-former, increasing the glass polymerization as confirmed in previous study on magnesium containing glasses [32,46]. This network modifier effect of $\mathrm{Ca}^{2+}$ and $\mathrm{Mg}^{2+}$ into DIAN systems have been also confirmed by the $\mathrm{Q}^{\mathrm{n}}$ distribution of the $\mathrm{Al}^{3+}$ ions which results constituted, for a percentage higher than $70 \%$, of $\mathrm{Q}^{4}$ species (data not shown). This result well compare to Al-BO and Al-NBO distribution previously discussed for these glasses.

The structural arrangement of $\mathrm{Mg}^{2+}, \mathrm{Ca}^{2+}$ and $\mathrm{V}^{5+}$ around the former ions $\mathrm{Si}^{4+}$ and $\mathrm{Al}^{3+}$ is described by the ratio $\mathrm{R}_{\mathrm{B} / \mathrm{C}}^{\mathrm{A}}=\mathrm{CN}_{\mathrm{T}-\mathrm{B}} / \mathrm{CN}_{\mathrm{T}-\mathrm{C}}$, normalized with respect to the number ratio $\mathrm{N}_{B} / \mathrm{N}_{C}$ of ions $B$ and $C$ in the cell $[46,51]$. A unit ratio will then denote a statistical (random) distribution of $B$ and $C$ ions surrounding $A$, strictly following their

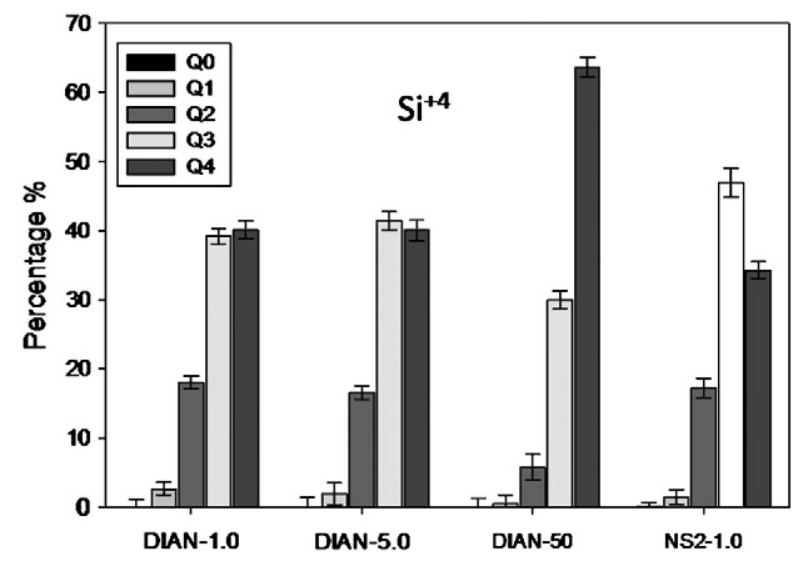

Fig. 10. Qn distributions of Silicon atoms.

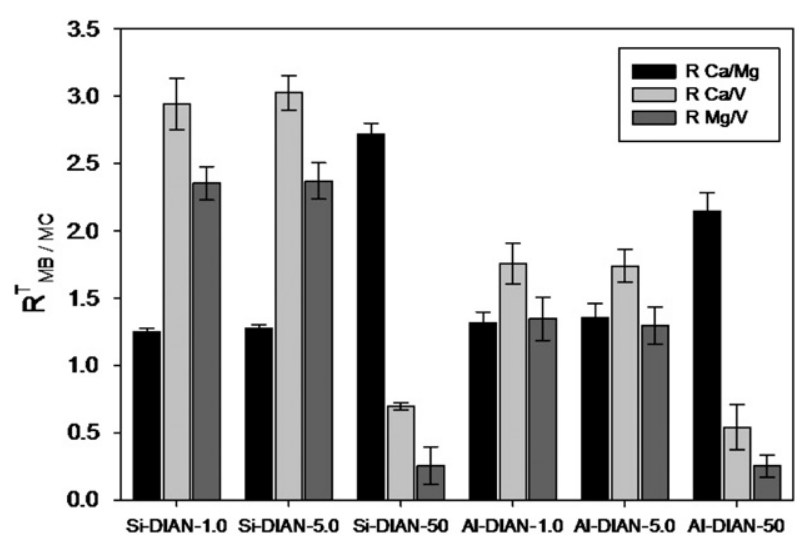

Fig. 11. $R_{M B / M C}^{T}$ ratios for $\mathrm{Si}$ (left) and $\mathrm{Al}$ (right) centers. $\mathrm{R}>1$ denotes preference of $\mathrm{A}$ (Si or $\mathrm{Al}$ ) for $\mathrm{B}$ coordination, whereas $\mathrm{R}<1$ indicates $\mathrm{C}$ preference. different concentration, whereas deviations from unity denote a non statistical environment around the central ion A (Fig. 11).

Fig. 11 shows similar values for DIAN-1 and DIAN-5 of $\mathrm{R}_{\mathrm{Ca} / \mathrm{Mg}}$ ratios, slightly higher than one, denoting a preference for $\mathrm{Ca}^{2+}$ instead of $\mathrm{Mg}^{2+}$ ions to surround both $\mathrm{Si}^{4+}$ and $\mathrm{Al}^{3+}$ ions. Moreover, for both DIAN glasses, $\mathrm{Ca}^{2+}$ and $\mathrm{Mg}^{2+}$ ions show a clear preference to surround the network former ions with respect to vanadium ions. DIAN-50 shows a net more pronounced preference for $\mathrm{Ca}^{2+}$ than $\mathrm{Mg}^{2+}$ to surround both $\mathrm{Si}^{4+}$ and $\mathrm{Al}^{3+}$ ions respect to DIAN-1.0 and DIAN-5.0. The main information that can be extrapolated from this analysis it is related to the evident tendency of $\mathrm{Ca}^{2+}$ and $\mathrm{Mg}^{2+}$ ions to surround $\mathrm{Si}^{4+}$ ions with respect $\mathrm{Al}^{3+}$ ions $\left(\mathrm{R}_{\mathrm{Ca}(\mathrm{Mg}) / \mathrm{V}}^{\mathrm{Si}}>2\right.$ and $\mathrm{R}_{\mathrm{Ca}(\mathrm{Mg}) / \mathrm{V}}^{\mathrm{Al}}>1$, respectively) for DIAN-1.0 and DIAN-5.0. Moreover, in DIAN-50 it is also evident that both $\mathrm{Si}^{4+}$ and $\mathrm{Al}^{3+}$ prefer to be surrounded by $\mathrm{V}^{5+}$ than $\mathrm{Ca}^{2+}$ and $\mathrm{Mg}^{2+}$.

\section{Conclusions}

The interatomic parameters obtained by the fitting procedure performed in this work allowed the glass structural characterization of vanadium containing glasses by using MD simulations. The results obtained in term of short range order of the glass structure well compare with the experimental values available for this system validating the computational procedure adopted. The network former role of $\mathrm{Si}^{4+}$ and $\mathrm{Al}^{3+}$ was confirmed for the composition analyzed. Moreover, strong compositional effect pointed out by comparing glasses belonging to the different base systems: presence of different cations in the glass formulation induced different network topology characterized by more or less packing of the polyhedra constituting the three dimensional glass structure, resulting into the $\mathrm{BO}$ and NBO distribution as well as into the $\mathrm{BAD}$ and $\mathrm{CN}$ distribution. The vanadium content in the glass systems didn't affect significantly the local structure of the $\mathrm{V}^{5+}$ for low vanadium content glasses (DIAN-1.0, DIAN-5.0 and NS2-1.0) and this result was explained considering that the vanadium concentration considered in this work are still too low to produce significant modification in the glass topology. On the contrary, the presence of different cations in the glass compositions analyzed induced significant changes into the medium structure of glasses: the presence of $\mathrm{Ca}^{2+}$ and $\mathrm{Mg}^{2+}$ instead of the $\mathrm{Na}^{+}$as modifiers, results into a more packed glass network characterized by higher $\mathrm{Q}^{\mathrm{n}}$ contribution. Also, the short and medium range order structural analysis of the glasses containing higher amount of $\mathrm{V}$ (DIAN-50 and NP-60) show good accordance with experimental data, showing clear differences in terms of structure than the low-content vanadium glasses.

The computational procedure validated in this work could be used to investigate in detail the structural information ( $\mathrm{V}-\mathrm{V}$ distances, $\mathrm{V}-\mathrm{O}-\mathrm{V}$ linkages and $\mathrm{BO} / \mathrm{NBO}$ ) directly correlated to the electrical properties and the correlated conduction mechanism for glasses containing high concentration of vanadium.

\section{Acknowledgment}

We thank Dr. G. Giuli of the Department of Earth Sciences of the University Camerino for helpful discussions. 


\section{Appendix A. Supplementary data}

Supplementary data to this article can be found online at doi:10.1016/j.jnoncrysol.2011.02.002.

\section{References}

[1] D. Adler, Amorphous Semiconductors, CRC, Cleveland OH, 1971

[2] P. Boolchand, Insulating and Semiconducting Glasses, World Scientific, Singapore, 2000.

[3] S. Bhattacharya, A. Ghosh, Phys. Rev. B 66 (2002) 132203.

[4] G.D. Khattak, N. Tabet, L.E. Wenger, Phys. Rev. B 72 (2005) 104203.

[5] M. Faiz, A. Mekki, B.S. Mun, Z. Hussain, J. Electr. Spectr. Relat. Phenom. 154 (2007) 60.

[6] A. Ghosh, Phys. Rev. B 42 (1990) 5665

[7] N. Ichinose, Y. Nakai, J. Non-Cryst. Solids 203 (1996) 353.

[8] A. Mekki, G.D. Khattak, D. Holland, M. Chinkhota, L.E. Wenger, J. Non-Cryst. Solids 318 (2003) 193.

[9] N.F. Mott, J. Non-Cryst. Solids 1 (1968) 1.

[10] G. Austine, N.F. Mott, Adv. Phys. 18 (1969) 41.

[11] H.M.M. Moawad, H. Jain, R. El-Mallawany, T. Ramadan, M. El-Sharbiny, J. Am. Ceram. Soc. 85 (2002) 2655.

[12] H.M.M. Moawad, H. Jain, R. El-Mallawany, J. Phys. Chem. Solids 70 (2009) 224

[13] M. Leister, D. Ehrt, G. Von der Gonna, F.W. Breubarth, Phys. Chem. Glasses 40 (1999) 319.

[14] P. Chaurand, J. Rose, V. Brios, M. Salome, O. Proux, V. Nassif, L. Olivi, J. Susini, J.L. Hazemann, J.Y. Bottero, J. Phys. Chem. B 111 (2007) 5101.

[15] M. Schindler, F.C. Hawthorne, W.H. Baur, Chem. Mater. 12 (2000) 1248.

[16] P.Y. Zaavalij, M.S. Whittingham, Acta Crystallogr. B 55 (1999) 627.

[17] G. Giuli, E. Paris, J. Mungall, C. Romano, D. Dingwell, Am. Mineral. 89 (2004) 1640

[18] C. Mercier, G. Palavit, L. Montagne, C. Follet-Houttemane, G. Tricot, L. Montagne, C.R. Chim 5 (2002) 693.

[19] G. Tricot, L. Montagne, L. Develoye, G. Palavit, V. Kostoj, J. Non-Cryst. Solids $345 \& 346$ (2004) 56.

[20] H. Kim, O.H. Han, J.P. Kang, S.K. Song, Bull. Korean Chem. Soc. 30 (2009) 608

[21] Z. Szalay, J. Rohonczy, J. Non-Cryst. Solids 353 (2007) 295.

[22] L.D. Bogomolov, M.P. Glassova, O.E. Dubatovko, S.I. Reiman, S.N. Spasibkina, J. Non-Cryst. Solids 58 (1983) 71.

[23] B.S. Bae, M.C. Weinberg, J. Am. Ceram. Soc 74 (1991) 3039.

[24] G.E. Brown, G. Calas, G.A. Waychunas, J. Petiau, in: F.C. Hawthorne (Ed.), Review in Mineralogy Spectroscopic Methods in Mineralogy and Geology, 18, Mineralogical Society of America, Chelsea, 1988, p. 431.

[25] J. Wong, F.W. Lytle, R.P. Messmer, D.H. Maylotte, Phys. Rev. B 30 (1984) 5596.

[26] F. Farges, Y. Lefrère, S. Rossano, A. Berthereu, G. Calas, G.E. Brown Jr., J. Non-Cryst Solids 344 (2004) 176

[27] S. Gupta, N. Khanijo, A. Mansigh, J. Non-Cryst. Solids 181 (1995) 58

[28] L. Murawski, R.J. Barczynski, Solid State Ionics 176 (2005) 2145.

[29] M. Pnat, D.K. Kanchan, P. Sharma, M.S. Jayswal, Mater. Sci. Eng. B 149 (2008) 18

[30] M.M. El-Desoky, H.S.S. Zayed, F.A. Ibrahim, H.S. Ragab, Phys. B 404 (2009) 4125

[31] M.P. Kumar, T. Sankarappa, J. Non-Cryst. Solids 355 (2009) 295.

[32] A. Pedone, J. Phys. Chem. C 113 (2009) 20773.

[33] A. Bonamartini Corradi, V. Cannillo, M. Montorsi, C. Siligardi, J. Mater. Sci. 41 (2006) 2811

[34] A.N. Cormack, Y. Cao, Mol. Eng. 6 (1996) 183.

[35] A. Bonamartini Corradi, V. Cannillo, M. Montorsi, C. Siligardi, A.N. Cormack, J. Non-Cryst Solids 351 (2005) 1185.

[36] A. Pedone, G. Malavasi, M.C. Menziani, A.N. Cormack, U. Segre, Chem. Mater. 19 (2007) 3144.

[37] P. Jund, W. Kob, R. Jullien, Phys. Rev. B 64 (2001) 134303.

[38] D.R. Banhatti, A. Heuer, Phys. Chem. Chem. Phys. 3 (2001) 5104.

[39] A. Heuer, M. Kunow, M. Vogel, R.D. Banhatti, Phys. Chem. Chem. Phys. 4 (2002) 3185

[40] H. Lammert, A. Heuer, Phys. Rev. B 72 (2005) 214202.

[41] W. Smith, T.R. Forester, G.N. Greaves, S. Hayter, M.J. Gillan, J. Mater. Chem. 7 (1997) 331.

[42] E. Sunyer, P. Jund, R. Jullien, Phys. Rev. B 65 (2002) 214203.

[43] J. Horbach, H. Kob, K. Binder, Phys. Rev. Lett. 88 (2001) 125502.

[44] J. Du, L.R. Corrales, Phys. Rev. B 72 (2005) 1.
[45] J. Du, L.R. Corrales, J. Non-Cryst. Solids 352 (2006) 3255.

[46] A. Pedone, G. Malavasi, M.C. Menziani, U. Segre, A.N. Cormack, J. Phys. Chem. C 112 (2008) 11034.

47] A.N. Cormack, J. Du, T.R. Zeitler, Phys. Chem. Chem. Phys. 4 (2002) 3193.

[48] A. Pedone, T. Charpentier, M.C. Menziani, Phys. Chem. Chem. Phys. (2010), doi:10.1039/b924489.

[49] L. Linati, G. Lusvardi, G. Malavasi, L. Menabue, M.C. Menziani, P. Mustarelli, A. Pedone, U. Segre, J. Non-Cryst. Solids 354 (2008) 84

[50] A. Pedone, G. Malavasi, M.C. Menziani, J. Phys. Chem. C 113 (2009) 15723.

[51] A. Tilocca, A.N. Cormack, N.H. de Leeuw, Chem. Mater. 19 (2007) 95.

[52] A. Tilocca, J. Chem. Phys. 129 (2008) 084504.

[53] A. Tilocca, A.N. Cormack, J. Phys. Chem. B 111 (2007) 14256.

[54] A. Tilocca, A.N. Cormack, N.H. de Leeuw, Faraday Discuss. 136 (2007) 45.

[55] A. Tilocca, N.H. de Leeuw, J. Phys. Chem. B 110 (2006) 51.

[56] A. Tilocca, Proc. R. Soc. London Ser. A 465 (2009) 1003.

[57] J.S. Braithwaite, C.R.A. Catlow, J.H. Harding, J.D. Gale, Phys. Chem. Chem. Phys. 3 (2001) 4052.

[58] M. Seshasayee, K. Muruganandam, Solid State Commun. 105 (1998) 243.

[59] N.D. Afify, G. Mountjov, Phys. Rev. B 79 (2009) 024202.

[60] A.I. Priven, Glass Technol. 45 (2004) 244.

[61] Glass Sci, In Universal System of Glass Properties, 3.5, SciVision, Burlington, 1997.

[62] A. Pedone, G. Malavasi, M.C. Menziani, A.N. Cormack, U. Segre, J. Phys. Chem. B 110 (2006) 11780.

[63] J.D. Gale, A.L. Rohl, Mol. Simul. 29 (2009) 291.

[64] W. Smith, T.R. Forester, J. Mol. Graph. 14 (1996) 136

[65] G. Malavasi, A. Peodne, M.C. Menziani, Mol. Simul. 32 (2006) 1045.

[66] G. Malavasi, M.C. Menziani, A. Pedone, B. Civalleri, M. Corno, P. Ugliengo, Theor. Chem. Acc. 117 (2007) 933.

[67] X. Yuan, A.N. Cormack, J. Non-Cryst. Solids 283 (2001) 69.

[68] J. Du, A.N. Cormack, J. Non-Cryst. Solids 349 (2004) 66

[69] M. Montorsi, M.C. Menziani, C. Leonelli, G.C. Pellacani, A.N. Cormack, Mol. Simul. 24 (2000) 157

[70] B. Park, H. Li, L.R. Corrales, J. Non-Cryst. Solids 297 (2002) 220.

[71] P.Y. Zavalij, M.S. Whittingham, Acta Crystallogr. B55 (1999) 627.

[72] M. Schindler, F.C. Hwathorne, W.H. Baur, Chem. Mater. 12 (2000) 1248

[73] A.V. Chichagov, A.B. Belonozhko, A.L. Lopatin, J. Non-Cryst. Solids 35 (1990) 220.

[74] D.N. Anderson, R.D. Willett, Acta Crystallogr. B27 (1971) 1476.

[75] F. Marumo, M. Isobe, S. Iwai, Acta Crystallogr. B30 (1974) 1628.

[76] H.T. Evans, M.E. Mrose, Am. Mineralog. 40 (1955) 861.

[77] C. Calvo, R. Faggiani, Acta Crystallogr. B31 (1975) 603.

[78] S. Asbrink, L.J. Norrby, Acta Crystallogr. B26 (1970) 8.

[79] M.O. Keeffe, J.-O. Bovin, Am. Mineralog. 63 (1978) 180.

[80] T. Hattori, Y. Iwadate, K. Igarashi, J. Mochinaga, J. Mater. Sci. Lett. 7 (1988) 891.

[81] N. Thong, D. Schwarzenbach, Acta Crystallogr, Sect. A 35 (1979) 658.

[82] M. Okuno, K. Kawamura, J. Non-Cryst. Solids 191 (1995) 249.

[83] J. Du, J. Am. Ceram. Soc. 92 (2009) 87.

[84] W. Li, S.H. Garofalini, Solid State Ionics 166 (2004) 365

[85] I. Yasui, H. Hasegawa, M. Imaoka, Phys. Chem. Glasses 24 (1983) 65.

[86] Y. Waseda, H. Suito, Trans. Iron Steel Inst. Jpn 17 (1977) 82.

[87] D.A. McKewon, G.A. Waychunas, G.E. Brown, J. Non-Cryst. Solids 74 (1985) 325.

[88] G. Lusvardi, G. Malavasi, L. Menabue, M.C. Menziani, J. Phys. Chem. B 106 (2002) 9753.

[89] T. Taniguchi, M. Okuno, T. Matsumoto, J. Non-Cryst. Solids 211 (1997) 56.

[90] C.D. Yin, M. Okuno, H. Morikawa, F. Marumo, T. Yamanaka, J. Non-Cryst. Solids 80 (1986) 167.

[91] C.D. Yin, M. Okuno, H. Morikawa, F. Marumo, J. Non-Cryst. Solids 55 (1983) 131.

[92] G. Ori, C. Mugoni, M. Montorsi and C. Siligardi (in preparation).

[93] W. Loewenstein, Am. Mineral. 39 (1954) 92.

[94] P. McMillan, B. Piriou, J. Non-Cryst. Solids 55 (1983) 221.

[95] C.A. Scamehorn, C. A., Angell, Geochim. Cosmochim. Acta 55 (1991) 721.

[96] J.B. Murdoch, J.F. Stebbins, I.S.E. Carmichael, Am. Mineral. 70 (1985) 332.

[97] S.K. Sharma, B. Simons, H.S. Yoder Jr., Am. Mineral. 68 (1983) 1113.

[98] S.K. Lee, J.F. Stebbins, Am. Mineral. 84 (1999) 937.

[99] S.K. Lee, J.F. Stebbins, J. Non-Cryst. Solids 270 (2000) 260.

[100] D.J. Stein, F.J. Spera, Am. Mineral. 80 (1995) 417.

[101] L. Cormier, D. Ghaleb, D.R. Neuville, J.-M. Delaye, G. Calas, J. Non-Cryst. Solids 332 (2003) 255. 